\title{
Proposta de um Portal Web alinhado a Teorias de Aprendizagem para o Apoio ao Ensino de Programadores Iniciantes
}

\author{
Érico Amaral - ericoamaral@unipampa.edu.br - PPGIE/UFRGS, UNIPAMPA \\ Cesar Huegel - cesarhuegel@live.com - UNIPAMPA \\ Marina Gomes - gomes.marina93@gmail.com - UNIPAMPA \\ Liliane Becker - lilianebb@gmail.com - UNIPAMPA \\ Alex Camargo - alexcamargoweb@gmail.com - FURG, UNIPAMPA \\ Liane Tarouco - liane@penta.ufrgs.br - PPGIE/UFRGS
}

\begin{abstract}
This paper aims to present a proposal for a Web Portal as a Learning Object (LO) to support learning in a discipline of Algorithms and Programming. The study, described here, came from a survey of robust theoretical concepts recognized in the area of education, which served as the basis for building the portal, through the study and definition of the technologies to be adopted in the implementation of this solution. Finally, an experiment for evaluating the prototype Portal was conducted by students and teachers of disciplines involving algorithms and programming languages. The analysis of the result showed that the project meets the initial expectations of the public who used the system.
\end{abstract}

Resumo.Este artigo tem por objetivo apresentar a proposta de um Portal Web como um Objeto de Aprendizagem (OA) para o apoio ao ensino em uma disciplina de Algoritmos e Programação. O estudo, aqui descrito, partiu de um levantamento teórico sobre reconhecidos conceitos na área de educação, os quais serviram de base para a construção do Portal, passando pelo estudo $e$ definição das tecnologias a serem adotadas na implementação desta solução. Por fim, um experimento de avaliação do protótipo do Portal foi realizado por alunos e professores de disciplinas que envolvem algoritmos e linguagens de programação. A análise dos resultados permitiram inferir que o projeto atende as expectativas iniciais do público que utilizou o sistema.

\section{Introdução}

Os conteúdos abordados na disciplina Algoritmos e Programação são considerados importantes para o êxito na formação de alunos que ingressam em cursos na área de tecnologia, nos diversos níveis do ensino como: técnicos, tecnológicos, bacharelados e engenharias. Os conhecimentos adquiridos nesta disciplina vão da lógica de programação ao entendimento de conceitos e da abstração necessária para a resolução de problemas, princípios necessários para a formação de alunos da área de computação e afins (GINAT, 1996; FALCKEMBACH, 2013).

O objetivo principal abordado no estudo de algoritmos é reconhecer os conceitos básicos para o seu desenvolvimento, permitindo ao aluno uma visão crítica e sistemática necessárias para a construção algorítmica e programação. Contudo, é reconhecido que os estudantes nestas disciplinas apresentam um alto nível de dificuldade na compreensão dos conteúdos (SILVA et. al. 2014), o que é comprovado estatisticamente com uma taxa média de $60 \%$ de reprovação ou desistência nestas disciplinas (ROCHA, 1993). Dados atuais mostram que esta perspectiva ainda persiste, e que é objeto de estudo e pesquisa de diversos autores como Yang et al. (2014); Likke et al. (2014) e Giraffa et al. (2014). Os problemas relacionados a aprendizagem da programação vão 
desde uma base matemática precária dos alunos, até a dificuldade do estudante na resolução de problemas de forma algorítmica (CAMPOS, 2009).

A proposta desta pesquisa é levantar requisitos, analisar e implementar um Portal Web, para servir como solução de apoio ao processo de ensino e de aprendizagem em disciplinas de Algoritmos e Programação. Pretende-se que esta seja uma ferramenta computacional didática, fundamentalmente calcada sobre conceitos e métodos de aprendizagem como o Ciclo de Aprendizagem Experimental de Kolb, Aprendizagem Significativa e respeito aos diferentes estilos cognitivos, buscando, desta forma, disponibilizar uma estrutura objetiva e clara, visando proporcionar ao aluno um ambiente atrativo, motivador e de fácil utilização.

A fim de apresentar a construção desta pesquisa, este artigo está estruturado da seguinte forma: na seção 2 tem-se o referencial teórico, abordando aspectos fundamentais sobre o ensino de algoritmos; a seção 3 descreve a metodologia adotada para o planejamento e execução deste estudo; a seção 4 apresenta a implementação do Portal, com a definição dos métodos e tecnologias adotadas; os experimentos de validação do protótipo do Portal, com a visão de alunos e professores é apresentado e discutido na seção 5; por fim, a seção 6 descreve as conclusões alcançadas.

\section{Referencial Teórico}

Esta seção tem por objetivo apresentar um extrato de contribuições teóricas que serão utilizadas para a construção desta proposta.

\subsection{A formação de profissionais em Programação e TI}

Um dos maiores problemas das instituições de ensino superior brasileira é o alto índice de evasão. Cursos das áreas exatas (Ciências, Matemática e Computação) alavancam estes percentuais com taxas de muito próximas a $28 \%$. Esse valor é considerado alto, já que a média nacional, divulgada pelo INEP (Instituo Nacional de Estudos e Pesquisas Educacionais), é de 23\% (INEP, 2012). Ao observar pontualmente a área de computação, nota-se que as disciplinas relacionadas a algoritmos e programação são apontadas como responsáveis, ou contribuem de forma efetiva, para a evasão e reprovação nas primeiras etapas destes cursos.

A preocupação com elevado o número de evasão de alunos é reforçada também pela baixa procura pelas carreiras associadas às áreas de Ciências Exatas. Como efeito disto, sofre a economia e a sociedade. No que tange a evasão associada aos cursos de Computação, estudos realizados por diversos pesquisadores da área de Educação e Computação e do Ministério da Educação brasileiro (MEC) identificam que os alunos desistem dos cursos logo no primeiro ano do ensino superior. As disciplinas causadoras desta desistência estão associadas ao ensino de Cálculo e de Programação, incluindo a disciplina de Algoritmos (GIRAFFA \& MORAES, 2013).

No Brasil, a previsão da Associação Brasileira de Tecnologia da Informação e Comunicação (BRASSCOM) é que até 2016 haja um crescimento de $30 \%$ na área de TI (BRASSCOM, 2014). Projeções deste órgão também indicam que 78 mil novos profissionais serão demandados nos oito principais mercados de TI do Brasil em 2014, mas apenas 33 mil estudantes concluirão os cursos superiores nesses estados (Rio de Janeiro, São Paulo, Distrito Federal, Paraná, Minas Gerais, Bahia, Pernambuco e Rio Grande do Sul), resultando em um déficit de 45 mil profissionais. Segundo o IDC (2014) dos 174.161 matriculados nas principais carreiras do setor, como programadores ou analistas de sistemas, $87 \%$ abandonaram os cursos.

\subsection{Aprendizagem e Algoritmos}

As causas de insucesso para a disciplina de Algoritmos e Programação são acarretadas pela dificuldade na organização de raciocínio, elaboração de estratégias de resolução de 
problemas, lógica, atenção e concentração. Deste modo, pode-se afirmar que as habilidades de raciocínio lógico, tais como: tentar, observar, conjeturar e deduzir não estão sendo devidamente desenvolvidas pelos alunos nas aulas de algoritmos, interferindo diretamente em sua capacidade de construir soluções algorítmicas para problemas (BARCELOS et al. 2009).

$\mathrm{Na}$ grande maioria dos casos, o estudante não consegue desenvolver a competência de abstração de problemas, o que implica em um baixo desempenho nas disciplinas iniciais em cursos de nível superior, tais como, algoritmos, cálculo, álgebra, dentre outras (PIVA\& FREITAS, 2011). Buscando uma melhora no processo de ensino, tendo em vista a dificuldade na construção do raciocínio lógico e dos conhecimentos necessários para a implementação de algoritmos, diversos Objetos de Aprendizagem (OA) já foram desenvolvidos com intuito de auxiliar estudantes e professores, nesse processo de ensino. Dentre estas soluções, destacam-se alguns trabalhos correlatos a esta pesquisa, como: O Ambiente de Aprendizagem Adaptado para Algoritmos A4, proposto por Araújo e Falckembach (2006), abrange o conteúdo básico de algoritmos e exemplos que partem do abstrato para o concreto, permitindo ao aluno visualizar e compreender as operações realizadas pelo computador durante a execução de um programa. A interação do aluno com o ambiente é realizada da seguinte forma: o aluno digita os valores respectivos a cada variável de entrada do programa e acompanha o seu processamento na memória; O Lógica Fácil, um trabalho de Sampaio e Souza (2007), baseado nas três estruturas de controle de fluxos: sequencial, condicional (ou seleção) e repetição. Deste modo, o objetivo é que o aluno desenvolva o raciocínio lógico focado na solução do problema em nível computacional.

\subsection{Teorias de Aprendizagem}

Segundo teóricos da área da educação, todos enfatizam a necessidade do professor ajudar na construção do conhecimento significativo a partir de um conhecimento prévio do aluno. Na perspectiva construtivista, o computador é visto como uma ferramenta para construir alguma coisa: um documento, uma imagem, uma história, um relatório, um projeto, um website, etc. $\mathrm{O}$ aluno é ativo no processo de aprendizagem e constrói o seu próprio conhecimento. O aprendiz constrói alguma coisa e "aprende fazendo". $\mathrm{O}$ fato de o aprendiz estar construindo algo do seu interesse estimula uma aprendizagem significativa. Valente (1993) explica que "segundo esta modalidade, o computador não é mais o instrumento que ensina o aprendiz, mas a ferramenta com a qual o aluno desenvolve algo, e, portanto, a aprendizagem ocorre pelo fato de estar executando uma tarefa por meio do computador". Fica explícita a ideia de que com o "computador ferramenta" o aluno será o sujeito promotor de uma ação, ou seja, seu lugar deixa de ser o de espectador e passa a ser o de agente.

Papert (1986) sugeriu o termo construtivismo para designar a modalidade em que um aluno utiliza o computador como uma ferramenta com a qual ele constrói seu conhecimento. Valente (1993) afirma que Papert usou o termo construtivismo para "mostrar um outro nível de construção do conhecimento: a construção do conhecimento que acontece quando o aluno elabora um objeto de seu interesse, como uma obra de arte, um relato de experiência ou um programa de computador". Kolb (1984) apresenta quatro etapas que considera básicas para o aprendizado: a Experiência concreta, onde o educando implica-se na procura de soluções para problemas que lhe são significativos e, partindo de sua própria experiência e da percepção que dela tem, formula novos questionamentos; a Observação reflexiva, na qual o estudante confronta experiências concretas proporcionadas por aprendizagens anteriores com novos saberes; a Conceitualização abstrata, através desta o aluno procura analisar as ideias e busca uma compreensão intelectual da situação; e a Experimentação ativa, que descreve o 
envolvimento direto do aluno com o meio, a fim de testar as abstrações e trabalhar com o real, na busca por resultados.

A análise, observação e estudo apurado das teorias apresentadas nesta seção serviram de base para a construção do Portal para o apoio ao ensino de algoritmos, proposto nesta pesquisa, a fim de torná-lo um objeto de aprendizagem efetivo.

\section{Metodologia}

Motivados a partir da observação dos problemas de evasão descritos nas disciplinas de lógica e programação, esta pesquisa vislumbra a construção de uma ferramenta para o apoio ao processo de ensino e aprendizagem de algoritmos, a qual sirva de forma efetiva, para professores e alunos, como solução para a redução dos índices de desistência e reprovação.

A proposta aqui apresentada baseia-se na construção de um Portal Web como um centro aglomerador e distribuidor de informações que atendam alunos de algoritmos e programação com diferentes perfis cognitivos. Para a implementação deste projeto, visto a complexidade envolvida, as tarefas estarão dimensionadas em um conjunto de etapas, previamente definidas, conforme apresentado na Figura 01, onde se tem: como ponto inicial o levantamento de um robusto referencial bibliográfico e teórico sobre o ensino de algoritmos e teorias de aprendizagem (etapa 1); a etapa 2 constitui-se pela definição do Objeto de Aprendizagem e teorias envolvidas; a terceira fase contempla o estudo das tecnologias a serem adotadas na construção do Portal, assim como definição formal do projeto instrucional, abordando características de design, layout entre outros; na etapa 4 é realizada a inserção e alinhamento do OA às teorias de aprendizagem estudadas; a quinta etapa caracteriza-se pela prototipação do Portal e avaliação do mesmo por alunos e professores de disciplinas de algoritmos e programação; etapa 6 destina-se à observação e avaliação dos resultados obtidos por meio da enquete da etapa 5; por fim, na etapa 7 serão definidos os requisitos finais para construção do projeto e apresentação das conclusões preliminares do estudo.

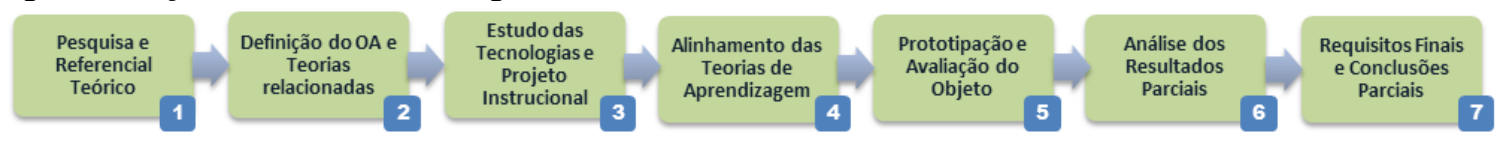

Figura 01. Etapas da metodologia

Entendendo que o método de pesquisa pode ser apresentado pela ordem dos processos envolvidos nesta e, que está fundamentalmente atrelado ao objeto pesquisado, este trabalho calca-se em um método científico (Nagel, 1969), se apropriando da observação, análise, descrição e síntese das informações coletadas, por meio da proposta de uma ferramenta para o auxílio à aprendizagem de algoritmos, com intuito de identificar a validade de sua proposição. A indução científica (Cannabrava, 1956) será adotada a fim de se coletar os argumentos factíveis para esta validação. Este estudo basicamente se caracteriza como uma pesquisa exploratória e descritiva, com coleta de dados realizada por meio de aplicação de questionários. O universo e indivíduos participantes desta são formados por alunos e professores dos cursos de engenharia da Universidade Federal do Pampa (UNIPAMPA), os quais estudam e ministram o conteúdo específico de Algoritmos e Lógica de Programação.

\section{Implementação}

Com o intuito de disponibilizar uma ferramenta de apoio ao ensino de algoritmos e programação, diferentes tecnologias foram avaliadas: animações, softwares tutores, aplicações locais e portais web. Dentre estas soluções, o Portal Web apresentou características pontuais para suprir as demandas necessárias de Objeto de Aprendizagem atendendo as necessidades dos estudantes e também possa ser utilizado como 
instrumento efetivo por professores, na tarefa da construção do raciocínio lógico e da programação. No que se refere às vantagens observadas, destacam-se: a capacidade de atender as demandas individuais, a disponibilidade de acesso aos conteúdos online, o aumento da exposição dos conteúdos, a inexistência de limites geográficos para o acesso à informação, tecnologias livre para o desenvolvimento, entre outros.

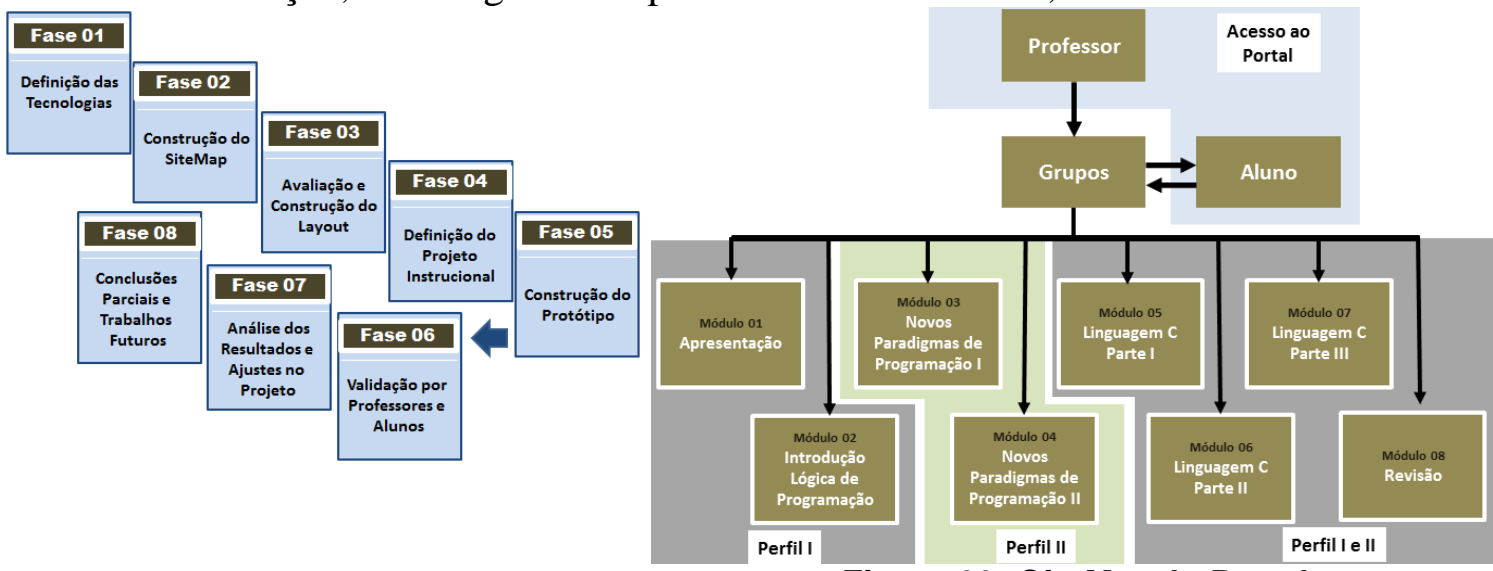

Figura 02. Projeto do Portal

Figura 03. SiteMap do Portal

Visto que o desenvolvimento de um software educacional não é uma tarefa simples, este projeto foi construído com base em um conjunto de ações, formalmente definidas, conforme demonstrado na Figura 02. Em cada fase elaborou-se um conjunto de ações, como segue:

Fase 01: Para o desenvolvimento do Portal, foi realizado um levantamento das tecnologias disponíveis, elencando quais seriam mais adequadas para a implementação, bem com sua viabilidade. A partir deste levantamento, as seguintes tecnologias foram escolhidas: HTML (HyperText Markup Language), CSS (Cascading Style Sheet), PHP (HiperText Preprocessor), jQuery e Hot Potatoes. O HTML é uma linguagem de marcação predominantemente usada para descrever o conteúdo ou dados na web. As CSS servem como estilo padrão para fontes, cores, espaçamentos dos documentos na web. O PHP é uma linguagem de script de uso geral, especialmente para o desenvolvimento de aplicações inseríveis dentro do HTML. Segundo Niederauer (2011), "O PHP é uma das linguagens mais utilizadas na web. Milhões de websites no mundo inteiro utilizam o PHP. A principal diferença em relação às outras linguagens é a capacidade que o PHP tem de interagir com o mundo web, transformando-o totalmente". Optou-se por utilizar o PHP pela grande disponibilidade de documentação e pelo domínio dos desenvolvedores deste portal. O jQuery é uma biblioteca JavaScript que se propõe, basicamente, a adicionar interatividade e dinamismo às páginas web de forma bastante descomplicada. Segundo Silva (2008), "Simplicidade é a palavra-chave que resume e norteia o desenvolvimento com jQuery". Já o Hot Potatoes é um software educacional utilizado para criar atividades de pergunta-resposta sob a forma digital para publicação na web no formato HTML. O seu código também foi inserido no Portal.

Fases 02, 03 e 04: Estas fases constituem-se na definição da estrutura do Portal (Figura 03), o qual foi projetado para conter oito módulos, sendo cada um constituído por um referencial teórico, um conjunto de aplicações (vídeos, áudios e animações), uma seção de atividades práticas e por fim uma seção com a avaliação do módulo (Figura 04). O Portal é constituído sobre um sistema de cadastro que permite o registro das ações do estudante a fim de que o professor possa acompanhar o desempenho e evolução dos mesmos no ambiente. O professor, por sua vez, poderá cadastrar Grupos nos quais os alunos serão vinculados. Estes Grupos poderão distinguir dois perfis de 
alunos: aqueles que irão estudar apenas uma linguagem de programação tradicional (Perfil I) e os que utilizarão outros paradigmas de programação (Perfil II) - conforme pode ser observado na Figura 03.

A definição do layout, padrão de cores, navegabilidade são atividades descritas na Fase 03, enquanto o alinhamento do Portal com as teorias de aprendizagem (ciclo de Kolb, Aprendizagem significativa e Aprendizagem autônoma e guiada) são tratadas na Fase 04, onde estes conceitos são devidamente inseridos nos conteúdos e formatação da proposta.

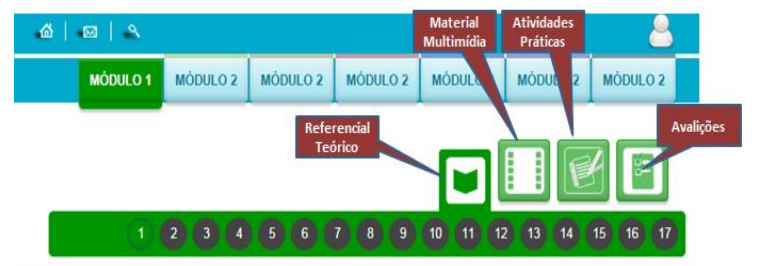

Figura 04. Estrutura de cada Módulo

Fase 05: Seguido da conclusão da estrutura do portal, uma das preocupações foi buscar conteúdos que atendessem todos os perfis cognitivos, portanto a quinta fase contempla construção do padrão de módulo. A elaboração do Módulo inicial, denominado Módulo 1, foi estruturado obedecendo às teorias de aprendizagem estudadas e, além disso, houve uma preocupação com a disposição das cores entre os módulos, visto que a percepção das cores contribui no processo visual e pode ser usada para expressar e intensificar a informação. O módulo está dividido em quatro recursos, os quais são: Referencial Teórico, Material Multimídia, Atividades Complementares e Avaliações. O material teórico que compreende a parte de conceitualização e exposição de exemplos sobre algoritmos são abordados em etapas onde, gradativamente, os alunos desfrutam os conhecimentos sobre a disciplina. O material multimídia visa atender aos usuários com perfil visual e auditivo, contemplando animações e vídeos educativos. Nas atividades complementares o aluno poderá testar a partir dos conhecimentos obtidos através dos materiais teórico e multimídia, reafirmando desta maneira as etapas da teoria de Kolb. No último material, foram propostas duas avaliações, onde abrangem um grupo de questões sobre como e o que fora exposto no módulo em questão. Esta avaliação objetiva mensurar se a estruturação do portal e módulo foram projetadas de maneira a atender as necessidades de cada perfil de usuário contribuindo na construção do aprendizado, tanto na visão do aluno como também na dos professores desta área de atuação.

Fases 06 e 07: Nesta etapa foram elaborados dois instrumentos para a coleta de informações sobre a usabilidade do Portal. O primeiro questionário foi direcionado aos alunos da disciplina de Algoritmos e Programação, o qual foi respondido por 90 estudantes de diferentes cursos superiores (Engenharias e Licenciaturas) do Campus Bagé da UNIPAMPA. O segundo instrumento foi construído a fim de coletar a impressão de professores de programação sobre o uso do protótipo. As respostas e discussões sobre o resultado destes experimentos são descritos na seção subsequente.

Fase 08: Esta é considerada a última etapa desta fase da pesquisa, neste ponto é elaborado o fechamento sobre as observações realizadas sobre as informações passadas por professores e alunos. A partir destes dados têm-se os requisitos necessários para fechar o desenvolvimento do Portal e colocá-lo em produção.

\section{Resultados e Discussões}

A fim de validar a proposta deste trabalho, um Portal Web como Objeto de Aprendizagem válido para o auxílio ao ensino de algoritmos, foi implementado um 
instrumento de pesquisa baseado em dois questionários. A finalidade da coleta de dados atua no sentido de avaliar a realidade em relação ao uso do protótipo disponibilizado. Os instrumentos foram organizados com intuito de observar aspectos e fenômenos relacionados com a visão de professores (08 participantes) e alunos (90 participantes) sobre o Módulo I do Portal, permitindo organizar as informações e ajustar o projeto. A Tabela 01 apresenta uma amostra das questões respondidas, tanto por alunos quanto por professores. Cabe ressaltar ainda, que os questionários seguem o modelo teórico de aceitação de tecnologia TAM (Technology Acceptance Model), o qual visa prever o impacto da tecnologia no comportamento humano (Davis, 1989). As respostas para tais perguntas foram disponibilizadas em uma escala likert de cinco pontos, distribuídas nos seguintes itens: concordo plenamente, concordo parcialmente, indiferente, discordo parcialmente e discordo totalmente.

Tabela 01. Instrumento de pesquisa respondido por alunos e professores

\begin{tabular}{|c|c|}
\hline Questões disponibilizadas aos Alunos & Questões disponibilizadas aos Docentes \\
\hline Se o Portal ficar a minha disposiçãoeu irei utilizá-lo? & $\begin{array}{l}\text { Você utiliza/utilizou alguma ferramenta de apoio (Objeto de } \\
\text { Aprendizagem) em suas aulas de Algoritmos? }\end{array}$ \\
\hline A ferramenta disponibiliza recursosnecessários paraa sua utilização? & $\begin{array}{l}\text { Em relação ao layout do Portal (cores, disposição de botões, aspectos } \\
\text { de interação, navegabilidade), o que achou do objeto? }\end{array}$ \\
\hline Eu acho o Portal uma ferramenta de fácil utilização? & $\begin{array}{l}\text { A organização dos conteúdos no Modulo I do Portal atendem ao tema } \\
\text { proposto (o aluno conseguiria aprender este conteúdo utilizandoo } \\
\text { ambiente)? }\end{array}$ \\
\hline $\begin{array}{l}\text { O Portal atendeu minhas expectativas em relação ao conteúdo } \\
\text { apresentado? }\end{array}$ & $\begin{array}{l}\text { Ao navegar pelo Portal consegui utilizar todos os recursos do Portal de } \\
\text { forma simples? }\end{array}$ \\
\hline $\begin{array}{l}\text { A estrutura do Portal (organização dos } \\
\text { conteúdos/atividades/avaliaçães) permitiu o uso intuitivo da } \\
\text { ferramenta? }\end{array}$ & $\begin{array}{l}\text { Eu utilizaria o Portal como ferramentade apoio nas minhas disciplinas } \\
\text { de algoritmos? }\end{array}$ \\
\hline $\begin{array}{l}\text { O padrão de cores adotado no Portal favoreceu a utilização da } \\
\text { ferramenta? }\end{array}$ & $\begin{array}{l}\text { A estrutura(conteúdo teórico, conteúdo multimídia, atividadese } \\
\text { avaliação) do Portal permite que um aluno construa o conhecimento } \\
\text { sobre o conteúdo de forma autônoma? }\end{array}$ \\
\hline Consideroo layout do Portal atrativo para as atividades propostas? & Dê uma nota de 1 à 5 ao Portal. \\
\hline
\end{tabular}

Avaliando algumas respostas dos alunos, percebe-se que a proposta do Portal é bem aceita como um objeto para o apoio em aulas de algoritmos. O grupo questionado relata que se tivesse o Portal a sua disposição em períodos anteriores, ou mesmo futuramente, em ambas as situações, os estudantes na sua maioria (45\% e 52\% respectivamente) concordaram plenamente com a utilização do Objeto de Aprendizagem, conforme apresentado nos Gráficos 01 e 02.

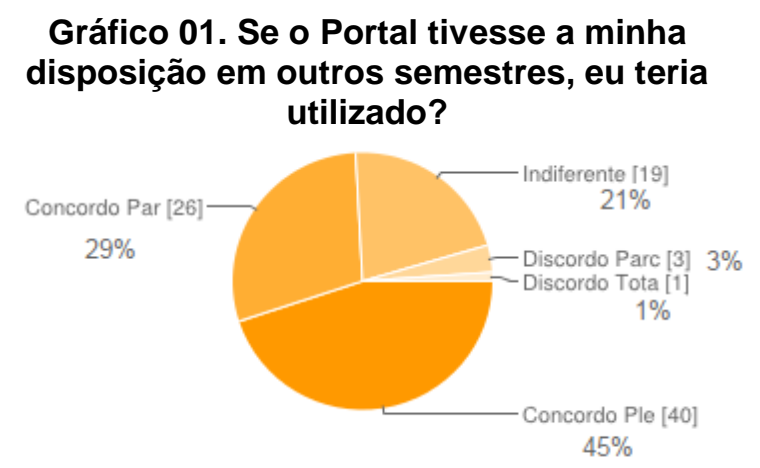

\section{Gráfico 02. Se o Portal ficar a minha disposição pretendo utilizá-lo?}

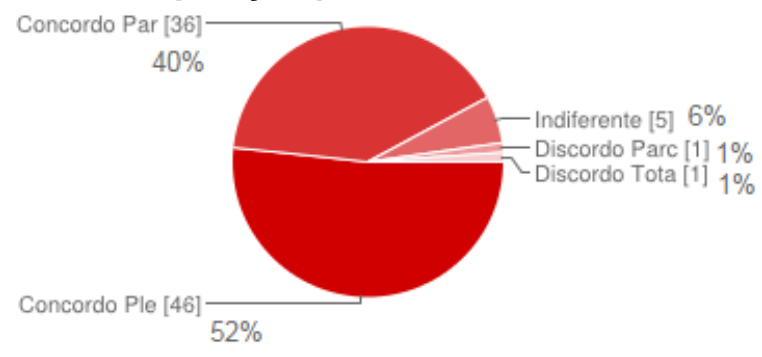

Em relação à facilidade de manipulação do Portal, considerando as informações, conjunto de recursos e organização destes, 69\% dos alunos afirmou se tratar de uma ferramenta simples de ser utilizada, $27 \%$ concordaram parcialmente com tal afirmação, $4 \%$ foram indiferentes e nenhum aluno discordou (Gráfico 03). Esta apreciação pode ser relacionada com a definição do layout e estrutura do protótipo, visto que estes foram elaborados com base em estudos de utilização de sistemas, padrão de cores e interação homem-computador. 
Gráfico 03. Dados os recursos, oportunidades e conhecimento necessários para utilizar o sistema, é fácil para mim usar a ferramenta?

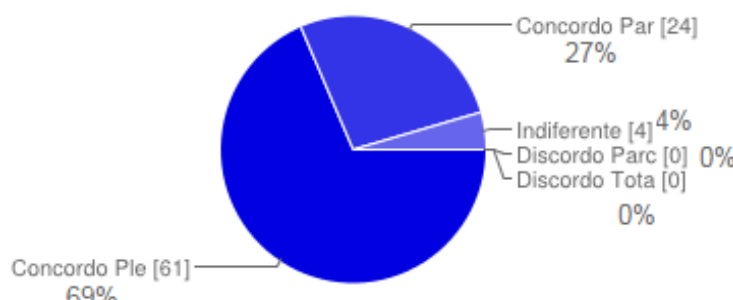

Gráfico 04. A organização dos conteúdos no Portal pode ser considerada didática?

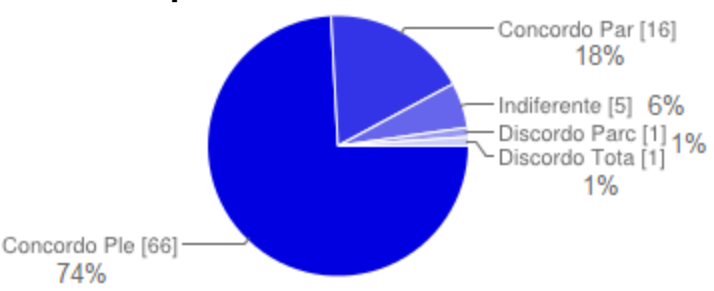

Ao observar aspectos educacionais, relacionados ao ensino de algoritmos (Gráfico 04), $74 \%$ dos estudantes concorda plenamente que as informações disponibilizadas no objeto estão organizadas de forma didática, fato que corrobora com a característica desejada ao Portal, uma vez que seus conteúdos foram dispostos e organizados respeitando teorias educacionais reconhecidas. Um aspecto interessante, demonstrado pela pesquisa, é constatado na resposta fornecida quando questionados se o conhecimento de lógica adquirido ao utilizar o Portal poderia auxiliar o aluno em outras áreas de seu curso (Gráfico 05). Neste caso, 17\% se manifestaram indiferentes e $8 \%$ discordaram parcialmente. Estes valores demonstram o fato de que muitos alunos não se motivam em aulas de algoritmos, pois não conseguem visualizar a importância do raciocínio lógico para as demais disciplinas em sua formação. Esta observação aponta para a necessidade de alinhar o conteúdo dos Módulos no Objeto a fim de que estes permitam o entendimento de sua relação com as demais áreas do conhecimento, aumentando, assim, o nível de motivação dos estudantes.

\section{Gráfico 05.0 conhecimento alcançado com o uso do Portal poderá me auxiliar em outras áreas de minha graduação?}

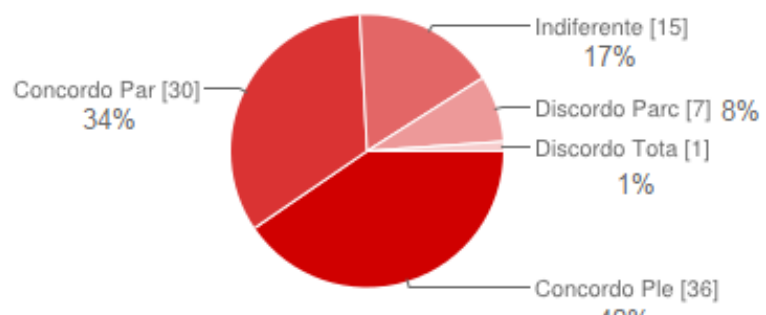

$40 \%$
Gráfico 06. Parecer dos Professores em relação ao layout do Portal.

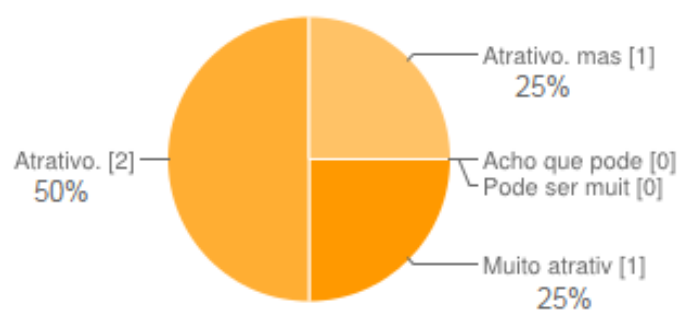

Por fim, avaliou-se a opinião dos professores em relação ao uso do Portal. Em um primeiro momento, os dados relevados se mostram pertinentes, visto que todos os participantes da enquete já haviam utilizado outros objetos de aprendizagem em suas aulas de algoritmos e a média de experiência destes professores com a disciplina de algoritmos ficou em torno de 5 anos. Em relação ao layout (cores, disposição de botões, aspectos de interação, navegabilidade), $50 \%$ dos professores consideraram o Portal atrativo, $25 \%$ muito atrativo e $25 \%$ disseram ser atrativo, contudo passível de melhorias, conforme Gráfico 06. Ao avaliar se na opinião do professor os alunos conseguiriam construir o conhecimento ao utilizar os recursos do Portal, 50\% concordaram plenamente e $50 \%$ concordaram parcialmente. Contudo $100 \%$ afirmaram que a ferramenta é de utilização simples e que adotariam o Portal em suas disciplinas de algoritmos. Comparando as informações obtidas tanto de alunos, quanto de professores, é possível observar que ambos os perfis apontaram a ferramenta proposta como uma solução factível, visto que as informações disponibilizadas, assim como a estrutura do Portal permitem ao discente explorar os recursos de forma autônoma, construindo o conhecimento sobre a área de algoritmos. O alinhamento das atividades ao ciclo 
experiencial de aprendizagem garantem a fluência sobre o tema, a partir de características como o ensino guiado, multimodalidade e feedback automático.

\section{Conclusão}

Este artigo apresentou a proposta de um OA para apoiar o processo de ensino/aprendizagem de algoritmos e programação. Dentre as inúmeras tecnologias disponíveis, elencou-se a construção de um Portal Web como solução para implementação deste OA. Com o intuito de ser uma ferramenta efetiva, o projeto instrucional contou com um conjunto de etapas racionalmente elaboradas. Visando atender o maior número de requisitos possíveis, a pesquisa contempla princípios e técnicas de engenharia de software, desenvolvimento de uma aplicação, assim como o estudo e alinhamento da estrutura e conteúdos do Portal, com teorias de aprendizagem fundamentalmente reconhecidas. Nesta etapa do estudo, foi construído e avaliado um protótipo do Objeto de aprendizagem a fim de verificar os níveis de aceitabilidade da ferramenta e seu potencial para servir como instrumento para o auxílio na construção do conhecimento aos estudantes. Para o levantamento de tais informações, professores e alunos participaram de um experimento, por meio do qual se concluiu que o referido Portal Web atende de forma satisfatória as demandas dos estudantes. Houve declarações, em diferentes momentos, sobre a aplicação possuir um caráter didático, sendo que a utilizariam se a mesma tivesse disponível. Corroboram com este parecer algumas colocações dos alunos como: "Acho que o acesso a atividades no portal deve continuar, com a finalidade de ajudar na realização das atividades e para auxílio de estudo para provas" e "Acredito plenamente no benefício que este portal traz para nós estudantes. Com o uso correto, observei que durante as aulas de Algoritmos $e$ Programação houve um melhor entendimento". A partir destas observações é factível apreciar que, o protótipo disponibilizado atende as demandas para o qual foi desenvolvido e, que a sua modelagem pode ser adotada como padrão para a finalização do projeto e construção dos demais Módulos da ferramenta.

\section{Referências Bibliográficas}

ARAÚJO, F. V.; FALCKEMBACH G. A. M. Experiências no aprendizado de algoritmos utilizando um ambiente de aprendizagem. RENOTE, v. 4, n. 1, 2006

BARCELOS, R. J. S.; TAROUCO, L.; BERCH, M. O uso de mobile learning no ensino de algoritmos. RENOTE, v. 7, n. 3, 2009.

BRASSCOM. Tecnologia sofre evasão universitária. Disponível em: <_http://www.brasscom.org.br/brasscom/Portugues/detInstitucional.php?

codigo $=27 \& \operatorname{cod} A r e a=3 \& \operatorname{codCategoria}=48>$. Acesso em 10 Nov 2014.

CAMPOS, R. L. B. L. Lógica de programação: Há como melhorar o aprendizado fugindo dos padrões estabelecidos nos livros didáticos e adotados pela maioria dos docentes? CLEI, Brasil, RS, Pelotas, 2009.

CANNABRAVA, Euryalo. Introdução à filosofia científica. São Paulo: Companhia Editora Nacional, 1956.

DAVIS, F. D.; BAGOZZI, R. P.; WARSHAW, P. R. User Acceptance of computer technology: a comparison of two theoretical models. Managesci., New York, v. 35, n. 8, p. 982-1003, 1989.

FALCKEMBACH, Gilse A. M.; ARAÚJO, Fabrício V. de. Aprendizagem de Algoritmos: Dificuldades na Resolução de Problemas. Anais SULCOMP, 2013.

GINAT, David. Efficiency of algorithms for programming beginners. In: ACM SIGCSE Bulletin. ACM, 1996. 
GIRAFFA, L. M. M. \& MORAES, M. C. Evasão na disciplina de algoritmos e programação: Um estudo a partir de fatores intervenientes na perspectiva do aluno. CLABES, 2013.

GIRAFFA, L. M. M.; MORAES, M. C.\&UDEN, L. Teaching Object-Oriented Programming in First-Year Undergraduate Courses Supported By Virtual Classrooms. In: The 2nd International Workshop on Learning Technology for Education in Cloud. Springer Proceedings in Complexity, 2014.

IDC Latin. IDC Analizethe Future, 2014. Disponível em: $<$ http://br.idclatin.com/prodserv/mktanalysis.aspx>. Acesso em: 10 Set 2014.

INEP. Instituto Nacional de Estudos e Pesquisas Educacionais. Sinopses do ensino superior. Disponível em: 〈www.inep.gov.br>. Acesso em: 01 Out 2014.

KOLB, D. A. Experiential Learning: experience as thesource of learninganddevelopment. Prentice-Hall, 1984.

LYKKE, M., COTO, M., MORA, S., VANDEL, N., \&JANTZEN, C. Motivating programming students by Problem Based Learning and LEGO robots. In: Global Engineering Education Conference (EDUCON, IEEE), 2014.

NAGEL, E. Filosofia da Ciência. São Paulo. Cultrix, 1969.

NIEDERAUER, J. Desenvolvendo Websites com PHP. 2. ed. São Paulo Novatec Editora, 2011.

PAPERT, Seymour. Constructionism: A New Opportunity for Elementary Science Education. A proposaltotheNational Science Foundation. Massachusetts Institute of Technology, Media Laboratory, Epistemologyand Learning Group, Cambridge, Massachusetts. 1986.

PIVA, D.; FREITAS, R., L. Estratégia para melhorar os processos de abstração na disciplina de Algoritmos. In: Congresso da Sociedade Brasileira de Computação, XXXI., 2011.

ROCHA, H. V. Representações Computacionais Auxiliares de Conceitos deProgramação. In: "Computadores e Conhecimento: Repensando a Educação". Editora Unicamp, 1993.

SAMPAIO, R. L.; SOUZA, A. C. Objetos digitais de aprendizagem: Uma ferramenta auxiliar no processo de ensino-aprendizagem da disciplina Informática Básica. In: Congresso de Pesquisa E Inovação da Rede Norte Nordeste de Educação Tecnológica, 2007.

SILVA, Maurício S. jQuery: A Biblioteca do Programador JavaScript. São Paulo. Novatec Editora, 2008.

SILVA, I. F. A.; SILVA, I. M. M.; SANTOS, M. S. Análise de problemas e soluções aplicadas ao ensino de disciplinas introdutórias de programação. Disponível em 〈http://www.eventosufrpe.com.br/jepex2009/cd/resumos/R1479-1.pdf >. Acesso em: 12 janeiro 2014.

VALENTE, José Armando. Diferentes usos do computador na educação. In: Computadores e conhecimento: repensando a educação. $1^{\mathrm{a}}$ ed. Campinas, NIEDUnicamp, 1993.

YANG, Tzu-Chi; YANG, Stephen JH; HWANG, Gwo-Jen. Development of an Interactive Test System for Students' Improving Learning Outcomes in a Computer Programming Course. In: Advanced Learning Technologies (ICALT), 2014 IEEE 14th International Conference on. IEEE, 2014. 